\title{
The Control Of Postoperative Pain Following Oral Surgical Procedures By Ibuprofen Or Acetaminophen
}

Eremias Kess *, Iskander Ayana, Gabra Crimi and Zere Senalat

*Corresponding Author : Eremias Kess, Department of Behavioral and Community Dentistry, Iran. Received date: September 02,2018;Accepted date : September 18,2018; Published date: September 22,2018.

Citation: Eremias Kess, The Control Of Postoperative Pain Following Oral Surgical Procedures By Ibuprofen Or Acetaminophen, J Dentistry and Oral Maxillofacial Surgery. Doi:10.31579/2643-6612/006

Copyright : (c) 2018 Eremias Kess. This is an open-access article distributed under the terms of The Creative Commons Attribution License, which permits unrestricted use, distribution, and reproduction in any medium, provided the original author and source are credited.

\section{Abstract}

Aim: The aim of this study was to compare the effects of anti-inflammatory (ibuprofen, $600 \mathrm{mg}$ ) and analgesic (Acetaminophen, $750 \mathrm{mg}$ ) drugs on postoperative pain.

Material and methods: Patients with indications for surgery were selected, and a total of 57 patients, 20 male (35.1\%) and 37 female $(64.9 \%)$ were included in the study. Of these, 26 patients were placed in the acetaminophen group, and 31 were placed in the ibuprofen group. The average age of the patients was 30 years. The following types of surgeries were included in the evaluation: clinical crown lengthening, gingivectomy, pre-prosthetic surgery, labial frenum and frenum lingual. The surgeries were performed by students in a postgraduate training program in periodontics. Subsequent surgery, postoperative period orientations were provided by the researcher, and the medication to be prescribed was selected at random allocation. Both medications were administered for 48-h periods. A visual analogue scale with values ranging from 0 to 10 , where 0 represented no pain and 10 represented maximum pain, was provided to the patients, and the patients were asked to rate their pain using this scale each time they took the medication. At the time of the follow-up visit, the patient data were given to the researcher and subsequently tabulated and applied to the statistical analysis (Mann-Whitney, $\mathrm{p}<0.05$ ).

Results: The results showed no significant difference in pain between medications ( $p>0.05)$.

Conclusions: There was no difference in postoperative periodontal surgery pain after the use of anti-inflammatory or analgesic drugs.

Keywords: Ibuprofen, acetaminophen, postoperative, surgery, oral, pain

\section{Introduction}

Dentistry is one area of science that is actively pursuing the search for pain relief and control. Difficulties associated with pain control are experienced in various areas of dentistry, including endodontic and postoperative treatments, trauma, and joint and muscle conditions $[1,2]$. From research focused on understanding the mechanisms involved in pain, resources such as medications to control pain have been developed, and many of these have also been shown to reduce inflammation [2].

The availability of pain medications is variable. In this study, two lowcost medications with easy access, known safety and pharmacology profiles, and wide acceptance in the medical field were selected $[3,4]$ : the analgesic drug acetaminophen $(750 \mathrm{mg})$ and the nonsteroidal, antiinflammatory drug ibuprofen $(600 \mathrm{mg})$. Ibuprofen acts by inhibiting cyclooxygenase, which produces prostaglandin through the arachidonic acid cycle [3,4]. Prostaglandins are potent agents, and their control prevents pain by preventing hyperemia in the microcirculation resulting from surgical trauma to soft and hard tissues [5].

Oral surgeries are performed for various reasons, such as for rehabilitation and/or functional purposes, disease prevention and/or treatment, or for improving the aesthetics of the smile. Given the clinical situations faced by dentists in daily practice, this study sought to further understand the control of postoperative pain in oral surgery.

The aim of the current study was to investigate the effect of antiinflammatory (ibuprofen, $600 \mathrm{mg}$ ) or analgesic (acetaminophen, 750 $\mathrm{mg}$ ) drugs on the control of postoperative pain in oral surgical procedures of relatively slight extent and not in itself hazardous to life.

\section{Materials and methods}

This manuscript has been conducted in full accordance with ethical principles, including the World Medical Association Declaration of Helsinki (2008) and it was approved by the Research Ethics Committee of the University General Hospital (Hospital Geral Universitário-HGU) under protocol number N. 2011-053.

The study was conducted in University of Cuiabá-UNIC-in the state of Mato Grosso, Brazil. Initially, the study size sample consisted of 134 patients, although several subjects were excluded during the study period for their lack of engagement or their desire to discontinue the research study. In total, this study assessed a sample of 57 patients with an average age of $30+6,3$ years. Of these, 26 patients were administered acetaminophen (AG), and 31 subjects were administered ibuprofen (IG).

The patients included had spontaneously visited the clinic for dental treatment and were then referred to the specialization course for screening. All patients were evaluated and received dental treatment, including those without indications for surgery. However, only those patients with indications for surgical procedures, such as an in clinical crown lengthening, gingivectomy, labial and lingual frenum, and pre-prosthetic surgery, participated in the study. The surgical procedures were routinely performed with mepivacaine hydrochloride $2 \% \mathrm{HCl}$ at a ratio of $1 / 100,000$ to epinephrine (Mepiedre, $100 \mathrm{DFL}$ ).

The exclusion criteria included the following: underage patients; those allergic to substances present in the medications; those with peptic ulcers, gastritis, or suspected pregnancy; those who did not take the medications or follow the postoperative recommendations; and those with underlying conditions that could pose health risks.

The professionals who performed the surgeries were students in the specialization course. However, the same professional was responsible for all postoperative care in all cases. 
All patients were provided guidance on post-surgical care and were told to contact the hospital by phone if they had any doubts or symptoms after surgery. Moreover, to assess general patient health, the patients were called during the first $24 \mathrm{~h}$ after surgery.

The patients were instructed to self-administer either $750 \mathrm{mg}$ acetaminophen every 8 hours for 2 days or $600 \mathrm{mg}$ ibuprofen every 8 hours for 2 days.

Pain assessment was performed using a visual analog scale (Figure 1). The chart was provided to the patients during the immediate postoperative period, and the patients were instructed how to use the chart to rate their pain on a scale from 0 and 10 when taking the medication. According to this scale, 0 represented no pain, while 10 represented the greatest level of pain possible. These scores were applied only during the first 2 days after the procedure. When the patients returned for the postoperative visit, they returned the scales with the completed score assessments. At this time, patients were excluded if they had not taken the medications or failed to follow the guidelines.

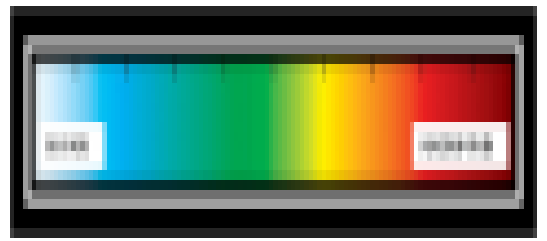

Figure 1 : Visual Analogue Scale (VAS) utilized in the study.

The data were organized and divided according to the AG and IB patient groups. The statistics tests used was Mann-Whitney, KruskalWallis, and Chi-square statistical tests, and the 5\% significance level was applied for all analyses.

\section{Results}

Initially, 134 patients were invited to participate in the study. Of these, 77 were excluded, which resulted in a total patient sample of 57 individuals. Of these, 20 were male $(35.1 \%)$ and $37(64.9 \%)$ were female patients. For the comparison of gender, a larger sample of women was analyzed $(\mathrm{p}<0.05)$. The minimum age of the patients was 21 years, and the maximum age was 40 years (Table 1 ).

\begin{tabular}{|l|c|c|}
\hline \multicolumn{1}{|c|}{ Frequency } & Percentage \\
\hline Male & $* 20$ & $35.1 \%$ \\
\hline Female & $* 37$ & $64.9 \%$ \\
\hline Total & 57 & $100.0 \%$ \\
\hline
\end{tabular}

Table 1 : Relative frequency of patient gender in the study. Discussion

This study compared the efficacy of acetaminophen $(750 \mathrm{mg})$ and ibuprofen $(600 \mathrm{mg})$ for the control of postoperative pain following oral surgical procedures and found no differences between pain drugs. Similar results have been observed in studies with comparable methodology [6,7] as well as in studies focused on other areas of health with greater systemic involvement. It should be noted that these two medications can be used as antipyretic drugs and can also be used by lactating women [3]. Moreover, ibuprofen has satisfactory antiinflammatory mechanisms of action. These drug profiles are due to the low molecular weights of the compounds and their low liposolubility [8-10].

The results of a randomized, double-blind clinical study that examined several medications found that the two medications evaluated exhibited few stomach or kidney problems when used therapeutically [11]. Moreover, in general, adverse drug reactions are poorly reported [11-13]. These results are consistent with those of the current study, as no side effects were observed in our sample of 134 patients.

Acetaminophen was selected due to its widespread use as an analgesic and because it has been thoroughly studied by many researchers. In comparison to other drugs, its systemic mechanism of action is satisfactory, although large-scale use has been shown to cause serious liver damage [14,15]
However, this side effect is not as relevant for the field of dentistry, as drugs for this use are generally administered for only a short period. Moreover, a study with rats evaluated the use of this drug for 4, 7, and 10 days and observed a significant decrease in the cellularity of the inflammatory infiltrate, consisting of monocytes, eosinophils, neutrophils, and natural killer (NK) lymphocytes, from the bronchoalveolar lavage fluid. Moreover, in addition to its drug safety profile, acetaminophen has been shown to aid cicatrization [16]. In addition, ibuprofen has also been shown to promote the closing of the arterial canal in premature children and has demonstrated few adverse reactions for the renal, brain, and mesenteric circulation. Interestingly, patients monitored over time showed no recurrence of the condition, which indicates that ibuprofen also appears to aid in cicatrization $[17,18]$.

Similar to acetaminophen, ibuprofen has also gained research interest due to its low rates of gastrointestinaldiscomfort and its low toxic potential [3]. The pharmacokinetics of ibuprofen demonstrate its short half-life with rapid elimination from the circulation [19] as well as its high antiinflammatory potential. Together, these effects of ibuprofen provide patients with a more comfortable and, in many cases, pain-free postoperative period [20,21].

The oral surgical procedures in this study were not very extensive and lasted approximately only 30-50 min. No relevant edema occurred, and no major incisions were performed. These facts may explain the similarity in the results observed between the drugs, as some patients may not have taken the medication if they did not have any painful symptoms. However, it should be noted that drug usage decisions were made by the patients themselves, and patients who did not follow the study guidelines were excluded from the sample.

The largest number of surgical procedures performed was for an increase in clinical crown size followed by gingivectomy of the anterior teeth with aesthetic indications. As the preponderance of these procedures may have represented a bias that could have interfered with the study design, the type of surgery performed and the pain levels associated were ranked in decreasing order to resolve this question. However, the statistical analyses demonstrated no significant differences in terms of post-operative pain between surgeries.

In addition, this study lost a significant portion of the sample population. As a result, more careful attention was paid to the sample selection, patient involvement, the provision of postoperative recommendations, and patient motivation to participate in the study.

\section{Conclusion}

Based on the methodology of this study, both medications were shown to be effective for controlling postoperative pain after periodontal surgery.

\section{References}

1. Jena A and Shashirekha G. Effect of preoperative medications on the efficacy of inferior alveolar nerve block in patients with irreversible pulpitis: A placebo-controlled clinical study. J Conserv Dent. 2013; 16:171-4

2. World Health Organization. The importance of pharmacovigilance: safety monitoring of medicinal products. Geneva. 2002.

3. Rainsford KD. Ibuprofen: pharmacology, efficacy and safety. Inflammopharmacology. 2009; 17:275-342.

4. Wahba H. The antipyretic effect of ibuprofen and acetaminophen in children. Pharmacotherapy. 2004; 24:280-4.

5. Edwards J, Meseguer F, Faura C, Moore RA, McQuay HJ and Derry S. Single dose dipyrone for acute postoperative pain. Cochrane Database Syst Rev. 2010; CD003227.

6. Perrott DA, Piira T, Goodenough B and Champion GD. Efficacy and safety of acetaminophen vs ibuprofen for treating children's pain or fever: a meta-analysis. Arch Pediatr Adolesc Med. 2004; 158:521-6.

7. Spencer JP, Gonzalez LS, 3rd and Barnhart DJ. Medications in the breast-feeding mother. Am Fam Physician. 2001; 64:119-26.

8. Chaves RG, Lamounier JA, César CC, Corradi MAL, Mello RP and Gontijo CM et al. Amamentação e uso de antiinflamatórios não esteróides pela nutriz: informações científicas versus conteúdo em bulas de medicamentos comercializados no Brasil. Rev Bras Saude Matern Infant. 2006; 6:269-76. 
9. Spigset $\mathrm{O}$ and Hagg S. Analgesics and breast-feeding: safety considerations. Paediatr Drugs. 2000; 2:223-38.

10. Lesko SM and Mitchell AA. The safety of acetaminophen and ibuprofen among children younger than two years old. Pediatrics. 1999; 104:e39.

11. Eneli I, Sadri K, Camargo C, Jr. and Barr RG. Acetaminophen and the risk of asthma: the epidemiologic and pathophysiologic evidence. Chest. 2005; 127:604-12.

12. Brvar M, Fokter N, Bunc M and Mozina M. The frequency of adverse drug reaction related admissions according to method of detection, admission urgency and medical department specialty. BMC Clin Pharmacol. 2009; 9:8

13. Secoli SR, Figueras A, Lebrao ML, de Lima FD and Santos JL. Risk of potential drug-drug interactions among Brazilian elderly: a population-based, cross-sectional study. Drugs Aging. 2010; 27:759-70.

14. Oscier CD and Milner QJ. Peri-operative use of paracetamol. Anaesthesia. 2009; 64:65-72.

15. Lacerda JT, Simionato EM, Peres KG, Peres MA, Traebert J and Marcenes W. [Dental pain as the reason for visiting a dentist in a Brazilian adult population]. Rev Saude Publica. 2004; 38:453-8.
16. Lauder SN, Taylor PR, Clark SR, Evans RL, Hindley JP, Smart K, Leach H, Kidd EJ, Broadley KJ, Jones SA, Wise MP, Godkin AJ, O'Donnell V and Gallimore AM. Paracetamol reduces influenzainduced immunopathology in a mouse model of infection without compromising virus clearance or the generation of protective immunity. Thorax. 2011; 66:368-74.

17. Moore N. Forty years of ibuprofen use. Int J Clin Pract Suppl. 2003; 28-31.

18. Pourarian S, Pishva N, Madani A and Rastegari M. Comparison of oral ibuprofen and indomethacin on closure of patent ductus arteriosus in preterm infants. East Mediterr Health J. 2008; 14:360-5.

19. Wahba $\mathrm{H}$. The antipyretic effect of ibuprofen and acetaminophen in children. Pharmacotherapy. 2004; 24:280-4.

20. Cherif A, Jabnoun S and Khrouf N. Oral ibuprofen in early curative closure of patent ductus arteriosus in very premature infants. Am J Perinatol. 2007; 24:339-45.

21. Carmo ED, Amadei SU, Pereira AC, Silveira VAS, Rosa LEB and Rocha RF. Prescrição medicamentosa em odontopediatria [Drugs prescription in pediatric dentistry]. Rev. Odontol UNESP, Araraquara. 2009; 38: 256-62. 